\title{
Bilateral Simultaneous Fracture of the Carpal Scaphoid Successfully Treated with Conservative Cast Immobilisation: A Case Report
}

\author{
Traitement Efficace D'une Fracture Bilaterale Et Simultanee De L'os Scaphoide Utilisant \\ L'immobilisation Platree: A Propos D'un Cas
}

W. Yinusa*†, O.Adetan ${ }^{\dagger}$, D. O. Odatuwa-Omagbemi ${ }^{\dagger}$, M. U. Eyo

\begin{abstract}
BACKGROUND: The scaphoid is the most prominent of the carpal bones in the first row and the most frequently fractured of all the carpal bones. Bilateral simultaneous scaphoid fractures are uncommon.

OBJECTIVE: To report bilateral simultaneous fractures of the carpal scaphoid bones and their successful treatment with bilateral thumb spacia casts

METHODS: A 28-year-old medical practitioner presented with a day history of painful swollen wrists following a fall on both outstretched hands. He was fully examined and had both wrists $\mathrm{X}$-rayed. He was subsequently treated with bilateral below elbowthumb spica POP cast.

RESULTS: He had previously been healthy until this fall. Physical examination showed a healthy looking young man in pain. There were swelling and tenderness over both anatomical snuff boxes with assoociated limitation of movements at the wrists. X-rays revealed an undisplaced scaphoid wrist fracture and proximal pole fracture on the right and left respectively. He was successfully treated with bilateral below elbow thumb spica POP cast applied over a period of eight weeks.

CONCLUSION: Although recent opinions tend to favour internal fixation for bilateral simultaneous fractures of the scaphoid bones to avoid prolonged cast immobilization and loss of man hours at work, they can be successfully treated with conservative cast immobilisation with comparatively early return to full activity. WAJM 2010; 29(6): 425-428.
\end{abstract}

Keywords: Scaphoid, bilateral simultaneous, fractures.

\section{RÉSUMÉ}

CONTEXTE: l'os scaphoïde est le plus gros des os de la première rangée du carpe. Il est souvent sujet à des fractures par rapport aux autres os constituant le carpe. La fracture bilatérale et simultanée des os scaphoïdes est rarement observée.

OBJECTIF: décrire un cas de fracture bilatérale et simultanée de l'os scaphoüde et l'efficacité d'un traitement conservateur par immobilisation plâtrée bilatérale du pouce.

METHODES: nous rapportons le cas d'un médecin praticien de 28 ans qui s'est présenté pour une douleur et oedème des 2 poignets suite à une chute sur ses 2 mains. La radiographie standard des 2 poignets a révélé une fracture bilatérale et simultanée des 2 os scaphoïdes. Le traitement s'est fait par plâtre anté-brachial bilatéral prenant les coudes jusqu'aux pouces (plâtre spica POP).

RESULTATS: le patient n'avait pas d'antécédents pathologiques notables jusqu'à sa chute. L'examen physique a montré un jeune patient en bonne santé mais souffrant d'une douleur aigue. Les 2 poignets étaient oedèmatiés et sensibles au niveau de la tabatière anatomique et de façon bilatérale avec une limitation de l'amplitude des mouvements de l'articulation. L'examen radiologique a montré une fracture non déplacée du scaphoïde droit et du pôle proximal du scaphoïde gauche. Le patient a été traité efficacement par plâtre antébrachial prenant les coudes jusqu'aux pouces du type spica POP pendant 8 semaines.

CONCLUSION: les pratiques récentes tendent vers la fixation interne des fractures bilatérales et simultanées des os scaphoüdes afin d'éviter les immobilisations prolongées et par conséquent la baisse de la productivité économique. Cependant, ces fractures peuvent être traitées et avec succès par un traitement conservateur basé sur une immobilisation plâtrée et n'empêchent pas une reprise relativement rapide des activités professionnelles. WAJM 2010; 29(6): 425-428.

Mots clé: scaphoïde, simultanée bilatérale, fractures.

Departments of Trauma and Orthopaedic Surgery Radiodiagnosis, National Orthopaedic Hospital Igbobi.

*Correspondence: P.M.B, 2009, Dr. W. Yinusa, Department of Trauma and Orthopaedic Surgery, Yaba, Lagos. E-mail: boboyinus@yahoo.com Abbreviations:AP, Antero-posterior; DISI, Distal intercalated segmental instability. 


\section{INTRODUCTION}

The scaphoid bone lies obliquely across the two rows of carpal bones. ${ }^{1}$ It is the most frequently fractured carpal bone constituting about $71-75 \%$ of carpal fractures. About $5-12 \%$ of such fractures are associated with other fractures around the wrist. Only about one percent of scaphoid fractures are bilateral. Simultaneous occurrence of bilateral scaphoid fractures is even rarer. A fall on outstretched hands with the wrist hyperextended to about $95^{\circ}$ is the usual mechanism of injury. ${ }^{1,2}$

Diagnosis is usually both clinical and radiological. A repeat X-ray may be required after two-three weeks of injury if diagnosis is not obvious on initial Xrays.

The management of acute scaphoid fracture is controversial. ${ }^{3}$ The factors considered include: the age, occupation of patient, hand dominance, bilaterality, displacement and the type or class of fracture described. However, about 88 $95 \%$ of acute scaphoid fractures are said to heal with conservative treatment using casts immobilisation. ${ }^{1,4}$ Nevertheless, for bilateral scaphoid fractures, and by reasons of sports, social life, and occupation, open reduction and internal fixation or percutaneous fixation are considered reasonable alternative treatment modalities. ${ }^{3,4}$ Displacement, late presentation, non-union, and association with other fractures are also indications for internal fixation with various type of screws. ${ }^{1,4,5}$

Complications such as non-union, delayed union, mal-union, wrist stiffness, wrist collapse, distal intercalated segmental instability (DISI), and osteoarthritis of the surrounding joints may result from delay in diagnosis and improper treatment.

Bilateral simultaneous fracture of scaphoid appears very rarely reported, nor its conservative management in a doctor.

\section{Case Report}

A 28-year-old male medical practitioner presented at the Casualty Department of the National Orthopaedic Hospital, Lagos in July 2006 with a days history of closed injury to both wrists. He was walking along a street in Lagos when he was attacked by hoodlums who tried to rob him. In the ensuing scuffle, he fell on both outstretched hands in an attempt to prevent himself from falling flat on the floor.

He experienced a sharp pain in both wrists and subsequently developed progressive swelling of both wrists with limitation of movements due to pain.

There was no injury elsewhere in the body, and no loss of consciousness. He initially applied icepacks and took a non-steroidal anti-inflammatory drug at home which did not give much relief hence, he presented to the centre the next day. Patient had no significant previous medical or surgical history. He was single; lived in Lagos and neither smoked nor took alcohol.

Physical examination revealed a healthy looking young man, in mild to moderate pain, not pale, icteric, or febrile. Important findings were in the musculoskeletal system where he had moderate swelling of both wrists.

Tenderness was marked at the anatomical snuff boxes with associated limitation of movement in both wrists due to pain. Findings in other body systems were essentially normal. He had two Xray views (PA and Lateral) of both wrists (Figures 1 and 2) which revealed an undisplaced scaphoid waist fracture and proximal pole fracture on the right and left respectively. There was associated subluxation of the scapho-capitotrapezoid joints but no fractures elsewhere.

Patients had bilateral below elbow thumb spica POP cast extending to the metacarpophalangeal joints of the fingers and the interphalangeal joints of the thumbs with the wrists in slight extension after manipulative reduction of subluxation. He had analgesic drugs. He was followed up at the clinic fortnightly. Pains had subsided at the first clinic visit.

After eight weeks in cast, the casts were removed and X-rays taken. On examination out of cast, swelling and tenderness had gone. However, there was stiffness of the wrist joints and reduction in grip strength. X-rays (Figures 3 and 4) showed both fractures were healed. He was subsequently placed on self physiotherapy as tolerated and went back to work. By four weeks after cast removal, i.e. 12 weeks post injury, he had regained full range of motion and grip strength at the wrists with return to full pre-injury activities.

\section{DISCUSSION}

Fractures of the carpal scaphoid are common. The incidence is estimated to be about 38/100,000 men and in Bengen Norway, it forms about two percent of all fractures and $11 \%$ of hand fractures. ${ }^{6}$ Only one percent of scaphoid fractures are bilateral.

Simultaneous occurrences of bilateral fractures are rarer. Most of these fractures occur in athletes and manual workers $^{3}$. A fracture of both scaphoid simultaneously in a medical practitioner who is not involved in any sporting activities is definitely a rare occurrence.

The diagnosis of scaphoid fractures is not always straight forward and in some cases is based on a high index of suspicion, as a reasonable number of such fractures may not be obvious on acute $\mathrm{x}$-rays. Fractures presenting within three weeks of injury are described as acute. ${ }^{7}$

A typical history of fall on the outstretched hands in a young adult male with resultant pain and tenderness at the wrist that is more marked in the anatomical snuffbox should arouse such suspicion. Our patient presented with this classical picture on both wrists. Some other cases are however, not that classical thus, leading to missed or delayed diagnosis and failure to offer appropriate early treatment with its negative implications on treatment outcome.

At least three to four views of Xrays have been suggested to be able appropriately delineate and classify these fractures. ${ }^{1,2,8}$ These include PA, lateral and oblique views (semi-pronated and semi-supinated views). Our patient had just two views(AP/Lat.) which were adequate for our purpose of diagnosis and treatment. Other less obvious fractures may need more X-ray views and other imaging modalities such as CT, MRI or bone scan for diagnosis. ${ }^{7,8,9}$

Proper radiological delineation helps to classify fractures, choose treatment and predict the vascularity of fracture fragments and thus, prongnosticate. ${ }^{1,7}$ Various attempts at classification include 


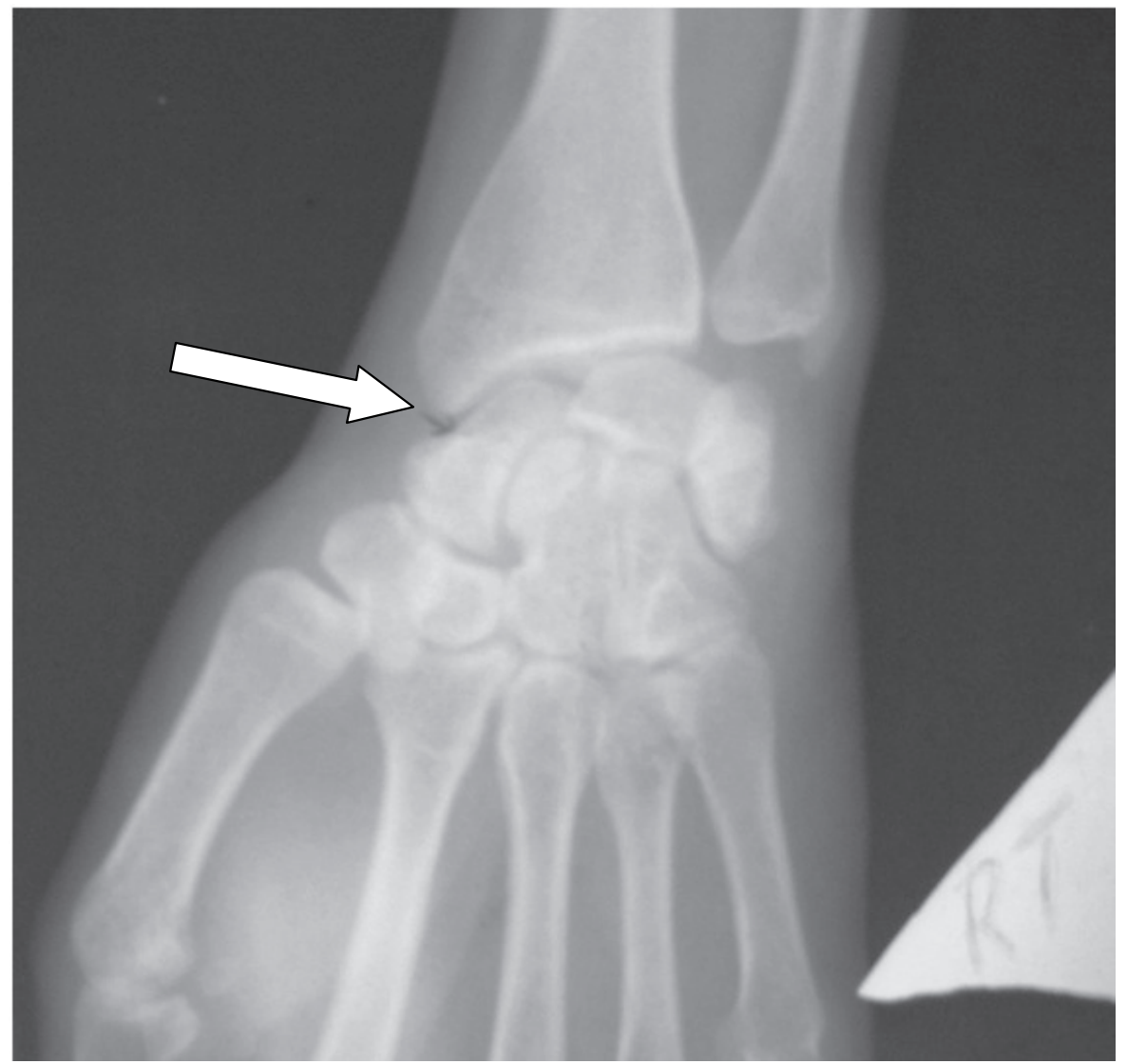

Fig. 1: Anteroposterior (AP) Radiograph of the Right Wrist at Presentation Showing Fracture of the Waist of the Scaphoid Bone (Arrow).

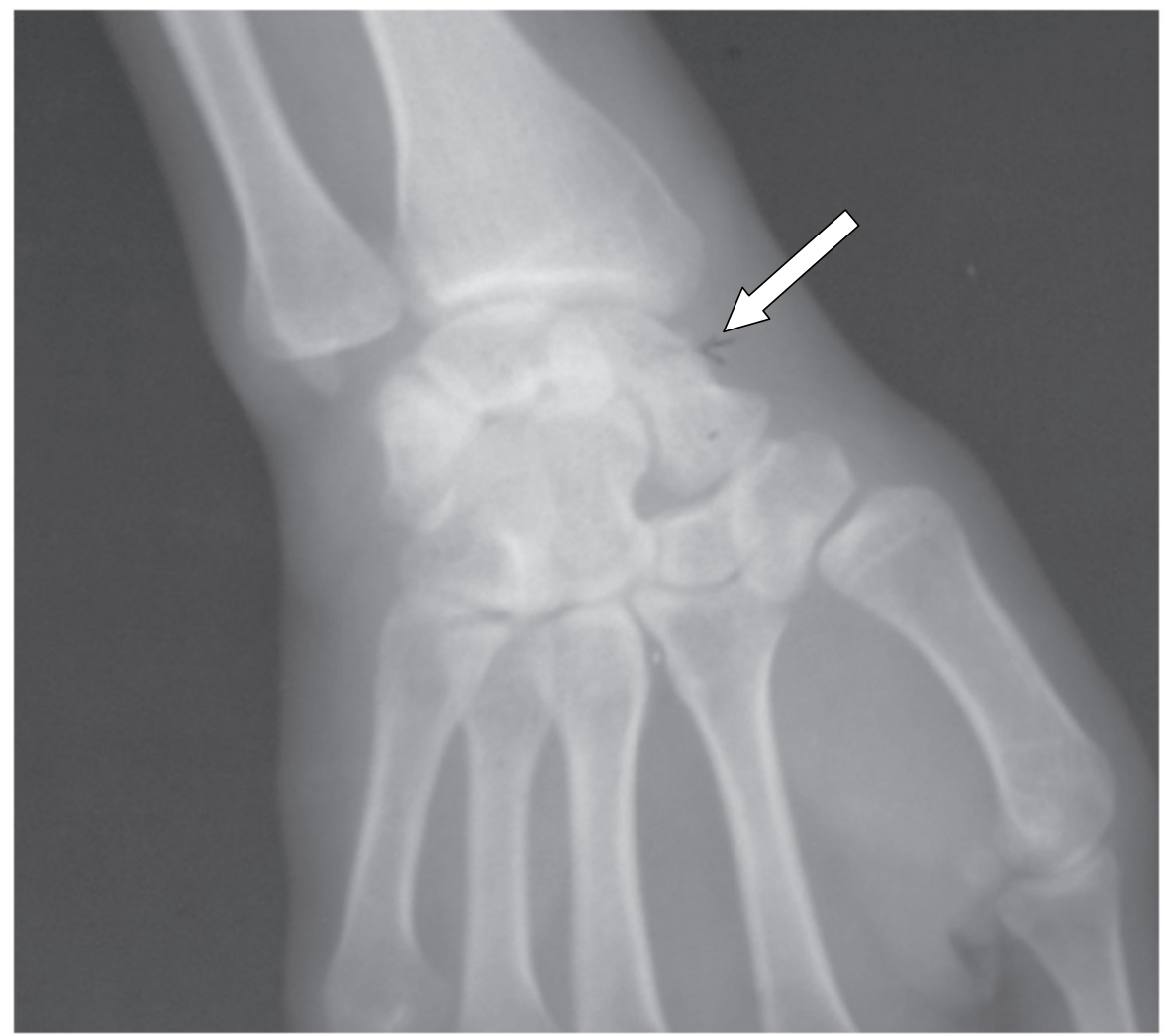

Fig. 2: Anteroposterior (AP) Radiograph of the Left Wrist at Presentation Showing Fracture of the Proximal Pole of the Scaphoid (Arrow). displaced and undisplaced fractures; stable and unstable fractures; transverseoblique, transverse and vertical oblique fractures; fractures of the tubercle, body or waist; and proximal, middle of distal third fractures. ${ }^{1,2,9}$ The waist is the most frequently fractured part of the bone. Our patient had a waist fracture on the right and a proximal pole fracture on the left.

The treatment of scaphoid fractures is controversial. ${ }^{3}$ Over $90 \%$ of undisplaced fractures of the scaphoid are still treated with cast immobilization. ${ }^{1,4}$ However, the long absence from work or sports, wrist stiffness, muscle weakness etc, that occur with prolonged cast immobilization, have made some authorities to argue that even in undisplaced fractures, internal fixation is an efficient alternative especially in simulataneous bilateral cases, and fractures occurring in surgeons, dentists, and other professionals who need efficient use of their hands at all times. ${ }^{3,8}$ Surgery is said to facilitate earlier return to work by about four weeks (compared with cast immobilization), and also to give a more predictable union rate. ${ }^{3}$ Bilateral scaphoid fractures may be treated with open reduction and internal fixation with screws to avoid the above complications. Clear indications for surgery include markedly displaced fractures, nonunions and late presentations. It is, however, important to note that in our patient, union occurred in both fractures about eight weeks post injury with conservative treatment in cast after which he returned to work. This time frame is quite comparable with patients offered surgery.

The type of cast used for immobilisation and the position of the wrist during immobilization have also generated some controversies. The conventional below elbow thumb spica or scaphoid cast with wrist in slight extension is quite popular. ${ }^{10,12}$ Union is usually achieved in this cast in 8-12 weeks with some cases extending to six months. Our patient had this cast applied as described, a day after injury and union was achieved bilaterally at eight weeks. Some authors have however, recommended the use of long arm above elbow 


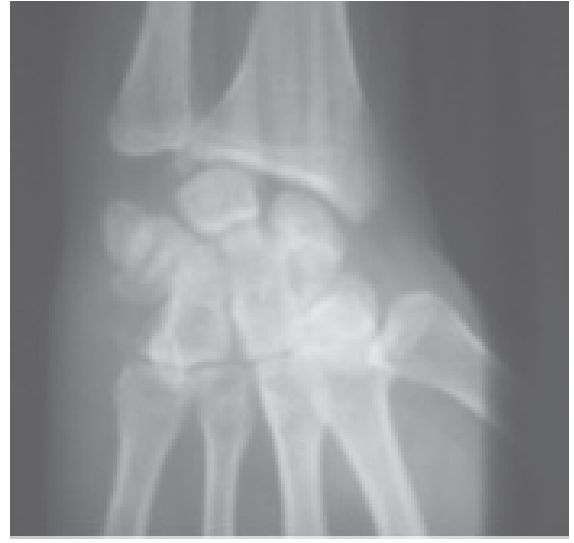

Figure 3: Anteroposterior (AP) View of the Right Wrist after eight weeks in Thumb Spica Cast. Note that the Scaphoid is Homogenous and you can hardly see the Fracture Site.

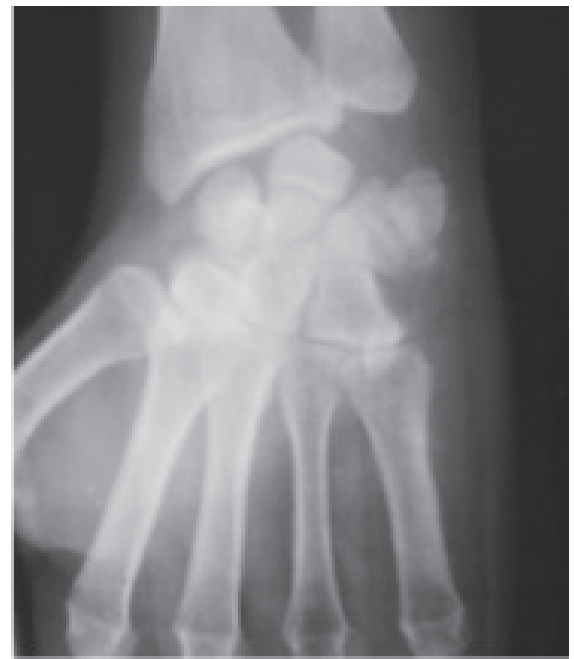

Fig. 4: Anteroposterior (AP) View of the Left Wrist after eight weeks in Thumb Spica Cast. Note that the Fracture Site is no longer visible. thumb spica cast for the first six weeks of treatment before reverting to the conventional short arm cast as above. This is said to reduce the effect of pronation and supination on the fracture fragments and to lead to shorter union time. ${ }^{9,11}$ The same authors also suggest that the wrist be immobilized in slight flexion to achieve better results. Nevertheless, most authorities still recommend that immobilization should be done with wrist in slight extension. ${ }^{1,2,12}$ Hambrigde et $a l^{12}$ found no significant difference in union when wrist was immobilized in flexion or extension of $20^{\circ}$ in their series but concluded that there was a significant reduction in extension movement at the wrist at six months in patients immobilized in flexion. They also opined that the use of the Colle's type of below elbow cast, which does not include the metacarpophalangeal joint of the thumb, is as effective as the use of the conventional below elbow thumb spica cast.

\section{REFRENCES}

1. Louis S, Warwick DJ, Nagayam S, Appley's System of Orthopaedics and Fractures. $8^{\text {th }}$ ed. Anold. London. 2001: 620-628

2. Chapman MW, (Ed) Chapman's Orthopaedic Surgery; 2. Philadephia. J.B. Linpincott. Co. 1996. 1307-1331.

3. Haddad FS, Goddard NJ, Acute percutaneous scaphoid Fixation. A pilot study. J Bone Joint Surg. 1998; 80-B: 95-99.

4. Saeden B, Lorkvist H, Ponzer S, Hohlund M, Fractures of the Scaphoid.
A prospective randomized 12 year follow-up comparing operative and conservative treatment. J. Bone Joint Surg. 2001; 83-B: 230-234.

5. Littlefield WG, Friedman RL, Ubaniak JR, Bilateral Non-union of the carpal Scaphoid in a child. A case report. J Bone Surg; 77-A: 124-126.

6. Leiv MH, epidermiology of Scaphoid Fractures in Bergen Norway, Scandinavian. J Plastic Recon. Hand Surg. 1999; 34: 423-426.

7. Kulkarni RJ, Wollstein R, Taryar R, Citron N, Pattern of healing of Scaphoid Fractures. The importance of vascularity. J Bone Joint Surg. 1999; 81-B: $50-90$.

8. Compson JP, Anatomy of Acute Scaphoid Fractures. A three Dimensional Analysis of Pattern. J Bone Joint Surg. 1998; 80-B: 218-24.

9. Gelberman HR, Wolock BS, Siegel DB, Current Concepts Review - Fracture and Non-unions of the carpal Scaphoid. J Bone Joint Surg. 1989; 71-A: 15601565.

10. Gamble JG, Simmons SC. Bilateral Scaphoid Fractures in a child. Clin Orthop. 1982; 162: 125-128.

11. Gellma H, Caput RJ, Carter V, Abuolafia A, Mckay M. Comparism of short and long thumb spica casts for non-displaced fractures of the carpal scaphoid. J Bone Joint Surg. 1989; 71A: 938-940.

12. Hambrigde JE, Desai VV, Achranz PJ, Compson JP, Davis TRC, Barton NJ, Acute Fractures of the Scaphoid. Treatment by cast immobilization with wrist in flexion or extension. J Bone Joint Surg. 1999; 81-B: 91-2. 